\title{
Methionine-stabilized nonclassical growth within self-assembled de novo gold nanoparticles in conjunction with secondary nucleation inhibition
}

Jitendra Sahu

Indian Institute of Technology Roorkee https://orcid.org/0000-0002-0720-4407

Shahbaz Lone

Indian Institute of Technology Roorkee

Kalyan Sadhu ( $\nabla$ sadhu@cy.iitr.ac.in )

Indian Institute of Technology Roorkee https://orcid.org/0000-0001-5891-951X

\section{Article}

Keywords: methionine (Met) controlled growth reaction, gold nanoparticle (AuNP), seed mediated growth

Posted Date: November 5th, 2021

DOl: https://doi.org/10.21203/rs.3.rs-961831/v1

License: (c) (i) This work is licensed under a Creative Commons Attribution 4.0 International License.

Read Full License 


\title{
Methionine-stabilized nonclassical growth within self-assembled de novo gold nanoparticles in conjunction with secondary nucleation inhibition
}

\author{
Jitendra K. Sahu, Shahbaz Ahmad Lone and Kalyan K. Sadhu* \\ Department of Chemistry, Indian Institute of Technology Roorkee, Roorkee - 247667, \\ Uttarakhand, India \\ Email: sadhu@cy.iitr.ac.in
}

\begin{abstract}
The key steps for seed mediated growth of noble metal nanoparticles involve primary and secondary nucleation, which depends upon the energy barrier and ligand supersaturation standards of the medium. Herein we report the unique case of methionine (Met) controlled growth reaction, which rather proceeds via impeding secondary nucleation in presence of citrate stabilized gold nanoparticle (AuNP). The interaction between freshly generated $\mathrm{Au}^{+}$and thioether group of $\mathrm{Met}$ in the medium restricts the secondary nucleation process involving further $\mathrm{Au}^{+}$reduction. This incomplete conversion of $\mathrm{Au}^{+}$results in a significant enhancement of the zeta $(\zeta)$ potential even at low concentration of Met. Furthermore, the aurophilic interaction of $\mathrm{Au}^{+}$controls the selfassembly process of the in situ generated emissive nucleated particles. Nucleation of primary particles on seed surface, their segregation and time dependent conversion to larger particles within self-assembly confirm the nonclassical growth, which has further been explored with Met containing bio-inspired peptides.
\end{abstract}


Growth reactions for gold nanoparticles as seed or biomolecules such as amyloid fibrils involve secondary nucleation as one of the major steps. ${ }^{1,2}$ Small molecule could suppress the secondary nucleation in the growth medium for amyloid beta peptides. ${ }^{3}$ However, appropriate small molecules as capping agents in the growth reaction for noble metals follow secondary nucleation leading to a variety of final shapes. ${ }^{4}$ Weak or strong binding efficiencies of such small molecules play an important role in the growth process in general, including the growth mechanism of anisotropic gold nanoarchitecture..$^{5}$ Compared to the high energy barrier involved in classical growth process by addition of atom to the crystal lattice, oriented attachment among nanoparticles involves low defect-free energy pathway for nonclassical growth. ${ }^{6}$ Intermediate synthesis at the molecular level has been traced for time dependent seed mediated gold nanocluster growth. ${ }^{7}$ Fluctuations of surface atoms successfully demonstrated the coalescence behavior of gold nanoparticle at $873 \mathrm{~K}$ within 1 hour time span on a silicon surface. ${ }^{8}$ Very recently, atomic scale mechanism of nonclassical nucleation of gold nanoparticle has been demonstrated by liquid-phase scanning transmission electron microscopy. ${ }^{9}$

The ligand's functional group and concentration are highly important in the pre-nucleation stage during gold nanoparticle synthesis. ${ }^{10} \mathrm{~A}$ wide range of shape evolution from spherical gold nanoparticle seed has been reported in presence of $\mathrm{Ag}^{+}$and halides through kinetic and surfacecontrolled growth. ${ }^{11,12}$ The combination of icosahedral gold seed and alkylamines shows growth into highly symmetric gold nanostars. ${ }^{13}$ Not only the small molecules, but also the biomolecules such as peptides or nucleic acids play an important role in the nucleation process for nanoarchitectures..$^{14-22}$ The growth reaction of octahedral and cubic gold nanoparticle seed in presence of amino acids and peptides containing cysteine ended up in asymmetric evolution. ${ }^{23,24} \mathrm{~A}$ handful of recent reviews have been reported focusing on the precisely defined anisotropic gold 
nanoparticle formation through growth reactions. ${ }^{25-27}$ Furthermore, a wide range of capping and reducing agents used for the selective growth along different facets of anisotropic gold seeds have been found to give a broad variety of final shapes. ${ }^{28-34}$ In our earlier report on the growth reaction involving AuNP as seed and hydroxylamine as reducing agent studied for all the amino acids, the positive $\zeta$ potential has been observed solely in presence of Met. ${ }^{35}$

In this current effort, we have focused on Met as small molecule for the stabilization of $\mathrm{Au}^{+}$in secondary nucleation step. The seed catalyzed $\mathrm{Au}^{+}$to $\mathrm{Au}^{0}$ conversion in the secondary nucleation step ${ }^{1}$ is significantly inhibited through the stabilization of $\mathrm{Au}^{+}-\mathrm{S}$ (thioether, Met) interaction $^{36}$. X-ray photoelectron spectroscopy (XPS) analysis after the Met controlled growth reaction confirms the stabilization of $\mathrm{Au}^{+}$species. The transmission electron microscopic (TEM) images with Met variation show stepwise formation of smaller sized nucleated gold nanoparticle (nAuNP) on parent AuNP seed surface, their detachment from seed and nonclassical growth of smaller individual to larger particles with time within the self-assembly of nAuNP (Scheme 1). The unique behavior from Met has been explored in the growth reactions with three bio-inspired peptides having variable Met residues.

Role of spectator seed in growth reaction. Citrate stabilized AuNP (15.0 $\pm 2.0 \mathrm{~nm}$, Figure S1) showing surface plasmon resonance (SPR) peak at $522 \mathrm{~nm}$ has been synthesized as seed for the growth reactions in the following steps. An additional small hump around $610 \mathrm{~nm}$ appears in absorbance spectra during $30 \mathrm{~min}$ incubation of $1.20 \mathrm{nM}$ AuNP with $9 \mathrm{mM}$ Met (Figure S2). Addition of $300 \mu \mathrm{M} \mathrm{Au} u^{3+}$ salt for the growth reaction in presence of excess hydroxylamine as reducing agent turns red-violet color solution immediately into blue and shows dual peak in the absorption (Figure S3). The time dependent absorbance spectra up to 30 min after growth reaction 


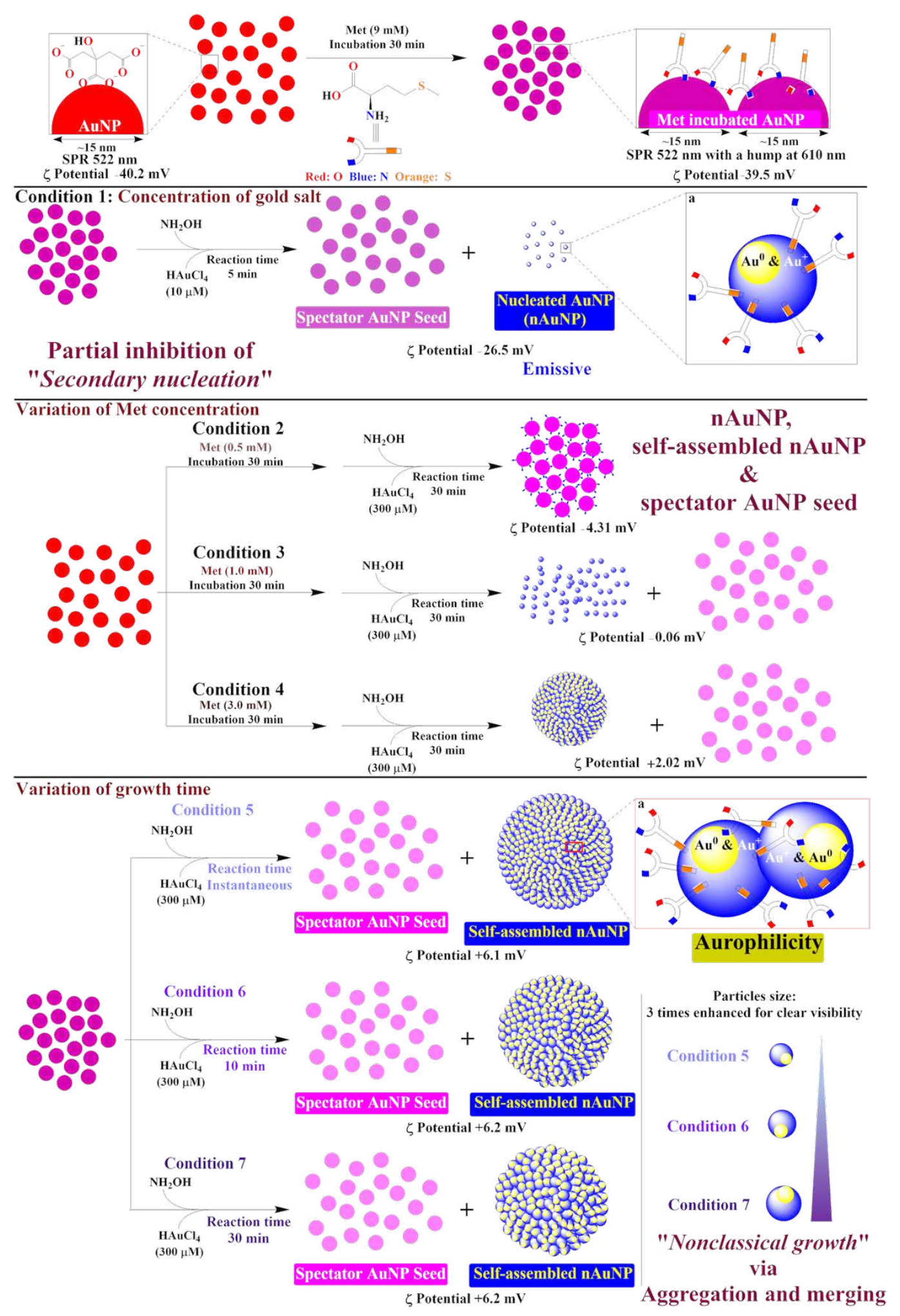

Scheme 1: Schematic illustration of the Met controlled partial inhibition of secondary nucleation followed by time dependent nonclassical growth. ${ }^{a}$ Blue and yellow spheres for $\mathrm{Au}^{+}$and $\mathrm{Au}^{0}$ have been used respectively to represent the 3:1 ratio between $\mathrm{Au}^{+}$and $\mathrm{Au}^{0}$ within nAuNP. These spheres do not represent the size of $\mathrm{Au}^{+}$and $\mathrm{Au}^{0}$. 
show the red-shifted SPR peak at $540 \mathrm{~nm}$ and the additional peak at $696 \mathrm{~nm}$ (Figure 1A and S3).

TEM image after 30 min of this growth reaction reveals spherical assemblies of average diameter $170 \mathrm{~nm}$ (Figure 1B). This observation is distinctly different from our earlier observations made regarding the remaining amino-acids ${ }^{35}$ Closely focusing on one such assembly, highly dense self-assembled nAuNPs has been observed (inset Figure 1B). Interestingly, TEM image reveals the maximum dimension $(\sim 11 \mathrm{~nm})$ of individual particle within the self-assembly; noticeably smaller than the parent seed. In addition to the self-assembled nAuNPs, presence of particles of parent seed dimension (Figure S4) in the same TEM grid confirms the role of seed as spectator only. The same growth reaction without parent seed shows no SPR peak, which endorses the important role of the parent seed in the Met controlled nAuNP synthesis.

\section{Methionine and $\mathrm{Au}^{3+}$ salt for segregation and self-assembly of nucleated particles. Met} concentration has been varied in stepwise manner to follow the role of spectator seed in the growth medium (Scheme 1, condition 2-4). The absorbance spectrum after the growth reaction in presence of $0.1 \mathrm{mM}$ Met concentration displays a small hump around $700 \mathrm{~nm}$ (Figure S5). In case of 0.3 mM Met, a clear additional peak has been generated at $696 \mathrm{~nm}$, which further shows blue shifts of $30 \mathrm{~nm}$ with increasing concentration of Met up to $1 \mathrm{mM}$. After the critical concentration of $1 \mathrm{mM}$ Met, absorbance measurements show continuous red shift till $696 \mathrm{~nm}$ with increasing Met concentration up to $9 \mathrm{mM}$ (Figure S5). After the growth reaction in presence of $0.5 \mathrm{mM} \mathrm{Met}$, nucleated particles of $\sim 6 \mathrm{~nm}$ size connected to the parent AuNP seed through (lllll 111 plane have been observed in the TEM study (Figure 1C). On contrary to the anticipated classical growth of seed, monitoring the same growth reaction with $1 \mathrm{mM}$ Met results in the development of $\sim 6.5 \mathrm{~nm}$ dimension segregated nAuNP (Figure S6). Growth reaction at $3 \mathrm{mM}$ Met concentration produces 
small self-assembly of nAuNPs (Figure S7) along with the existence of the spectator seeds in the TEM images.

The smaller sized nAuNP formation prompts us to monitor the emission properties of these assemblies. The luminescence spectrum confirms a weak emission at $430 \mathrm{~nm}$ from the solution after 30 min growth reaction by exciting the solution at $412 \mathrm{~nm}$ (Figure 1D). This weak emission is either due to the aggregation induced quenching within the self-assembly or due to the larger dimension $(\sim 11 \mathrm{~nm})$ compared to the reported emissive gold nanoclusters. ${ }^{37}$ In order to achieve better luminescence behavior from the nAuNPs, $10 \mu \mathrm{M} \mathrm{Au}{ }^{3+}$ salt has been introduced in the growth reaction (Scheme 1, condition 1). The dual absorbance nature after the growth reaction in presence of $10 \mu \mathrm{M}$ of $\mathrm{Au}^{3+}$ salt (Figure S8) shows blue shifts for both the peaks compared to the absorbance obtained for $300 \mu \mathrm{M}$ of $\mathrm{Au}^{3+}$ salt (Figure S3). Time dependent emission at $430 \mathrm{~nm}$ after the growth reaction in presence of $10 \mu \mathrm{M} \mathrm{Au}^{3+}$ salt shows initial enhancement followed by steady emission up to $30 \mathrm{~min}$ (Figure 1E). The excitation spectrum (Figure S9) confirms the position of the excitation wavelength at $412 \mathrm{~nm}$. No emissions have been observed for control experiments with the parent AuNP seed or the Met solution or the growth reaction of parent AuNP without Met incubation. The TEM image after 5 min of the growth reaction with $10 \mu \mathrm{M} \mathrm{Au}^{3+}$ salt clearly shows the formation of smaller non-aggregated nAuNPs of average diameter of $\sim 2.8 \mathrm{~nm}$ (Figure 1F). The high-resolution TEM (HRTEM, Figure 1G) image suggests the presence of both (1 111$)$ and (2 0 0) planes in the instantaneously generated nucleated nanoparticles. The variation of gold salt (10$800 \mu \mathrm{M}$ ) in the growth reaction results in the red shift trend of absorbance spectra (Figure S10).

Methionine sulfur for $\mathbf{A u}^{+}$stabilization inhibiting secondary nucleation. The $\zeta$ potential of the parent AuNP is negative due to the presence of capping citrate anions. The variation of $\mathrm{Au}^{3+}$ salt 

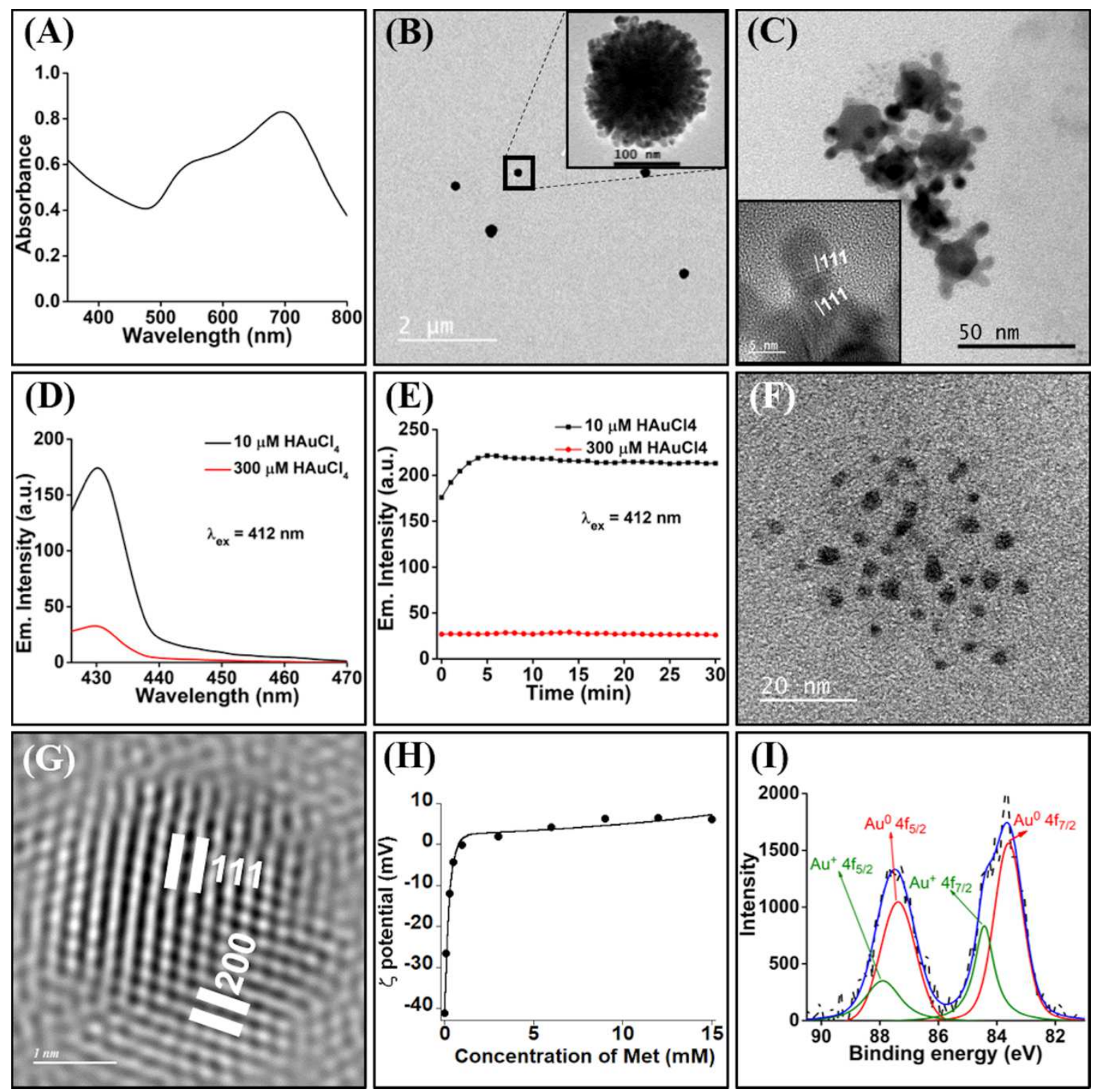

Figure 1: (A) Absorption spectrum and (B) TEM images (scale bar $2 \mu \mathrm{m}$ and $100 \mathrm{~nm}$ for inset) of the self-assembled nucleated particle after $30 \mathrm{~min}$ growth reaction of AuNP in presence of $9 \mathrm{mM}$ Met and $300 \mu \mathrm{M} \mathrm{Au}{ }^{3+}$; (C) TEM and HRTEM (inset) image of the in situ generated nucleated particle after 30 min growth reaction of AuNP in presence of $0.5 \mathrm{mM}$ Met and $300 \mu \mathrm{M} \mathrm{Au}{ }^{3+}$; scale bar $50 \mathrm{~nm}$ and $5 \mathrm{~nm}$ (inset); (D) emission spectra immediately after growth reaction of AuNP in presence of $9 \mathrm{mM}$ Met along with $300 \mu \mathrm{M} \mathrm{Au}^{3+}$ (red) and $10 \mu \mathrm{M} \mathrm{Au}^{3+}$ (black); (E) time dependent emission intensity after the growth reaction of AuNP in presence of $9 \mathrm{mM}$ Met along with 300 $\mu \mathrm{M} \mathrm{Au}^{3+}$ (red) and $10 \mu \mathrm{M} \mathrm{Au}^{3+}$ (black); (F) TEM (scale bar $20 \mathrm{~nm}$ ) and (G) HRTEM images (scale bar $1 \mathrm{~nm}$ ) of the nAuNP formed after 5 minutes growth reaction of AuNP in presence of $9 \mathrm{mM}$ Met and $10 \mu \mathrm{M} \mathrm{Au}^{3+} ;(\mathrm{H})$ Met dependent $\zeta$ potential variation after 30 min growth reaction of AuNP in presence of $300 \mu \mathrm{M} \mathrm{Au}{ }^{3+}$; (I) de-convoluted XPS spectra of $\mathrm{Au} 4 \mathrm{f}_{7 / 2}$ and $4 \mathrm{f}_{5 / 2}$ in the self-assembled nucleated particles showing the presence of $\mathrm{Au}^{0}$ (red) and $\mathrm{Au}^{+}$(olive); $\mathrm{AuNP}$ concentration for all the cases is $1.2 \mathrm{nM}$. 
in the growth reaction without Met incubation shows the enhancement in the SPR peak intensity (Figure S11) without any significant change in the $\zeta$ potential with respect to the parent AuNP seed. In presence of variable Met concentration $(0.1 \mathrm{mM}$ to $15 \mathrm{mM})$, the $\zeta$ potentials have been measured after $30 \mathrm{~min}$ of the growth reaction (Figure 1H). Addition of Met up to $1 \mathrm{mM}$ results in steady enhancement and reaches almost neutral $\zeta$ potential. Interestingly, when the concentration of Met increases from $1 \mathrm{mM}$ to $15 \mathrm{mM}$, the $\zeta$ potential values slightly enhanced up to $+6.5 \mathrm{mV}$. This trend confirms two different origins for $\zeta$ potential and $1 \mathrm{mM}$ Met concentration has been observed as a critical concentration, which echoes the Met dependent absorbance data and TEM images procured for this study.

In order to correlate the $\zeta$ potential trend and the self-assembly of the nAuNPs, XPS measurements (Figure S12) have been carried out for the mixture containing spectator seeds and self-assembled nAuNPs obtained from the growth reactions in presence of $9 \mathrm{mM}$ Met. Deconvolution studies of binding energy for $\mathrm{Au} 4 \mathrm{f}_{7 / 2}$ and $4 \mathrm{f}_{5 / 2}$ show the formation of $\mathrm{Au}^{+}$after the growth reaction (Figure 1I). Similar negative control studies on binding energies for the parent AuNP seed show no formation of $\mathrm{Au}^{+}$(Figure S13). The unusual stability of $\mathrm{Au}^{+}$in presence of Met in this growth reaction makes it extraordinary. At the initial nucleation step, hydroxylamine as a mild reducing agent reduces the added $\mathrm{Au}^{3+}$ ions to $\mathrm{Au}^{+}$ions. In the standard secondary nucleation process, seed AuNP participates in the reduction of $\mathrm{Au}^{+}$to $\mathrm{Au}^{0}$ followed by growth of the parent seed. ${ }^{1}$ In this Met controlled growth, secondary nucleation process is partially inhibited due to the unusual stability of freshly generated $\mathrm{Au}^{+}$by the available Met in the solution. ${ }^{36}$ The weak emission from this $\mathrm{Au}^{+} / \mathrm{Au}^{0}$ combination in water is similar to the previous report on weakly emissive $\mathrm{Au}^{0} @ \mathrm{Au}^{+}$-thiolate-based core-shell nanocluster in $75 \%$ ethanol. ${ }^{38}$ XPS study further confirms the presence of 3:7 ratio for $\mathrm{Au}^{+}: \mathrm{Au}^{0}$ after the growth reaction, while 4:6 ratio for 
$\mathrm{Au}^{3+}: \mathrm{Au}^{0}$ has been used in the growth reaction. The secondary nucleation step involving $\mathrm{Au}^{+}$ conversion to $\mathrm{Au}^{0}$ has thus been restricted by $75 \%$ in presence of Met. The self-assembly process of nAuNPs in this study has been observed after the growth reaction due to the aurophilic interaction ${ }^{39}$ between $\mathrm{Au}^{+}-\mathrm{Au}^{+}$present in these nucleated particles (Scheme 1).

The formation of $\mathrm{Au}^{+}$within nAuNPs is responsible for the significant change in the $\zeta$ potential measurements at low concentration $(0.1$ to $1 \mathrm{mM})$ of Met. The overall trend of $\zeta$ potential and Met concentration (Figure 1H) follows equation (1), where the two components are present due to individual interactions of $\mathrm{Au}^{+}$and $\mathrm{Au}^{0}$ with Met.

$$
\zeta=\zeta_{1} e^{-a(m)[M e t]}+\zeta_{2} e^{-b(1-m)[M e t]}
$$

In this equation, $\zeta_{1}$ and $\zeta_{2}$ are the coefficients in $\mathrm{mV}, a$ and $b$ are the constants and $m$ is the mole fraction of Met. After fitting the equation (1) for the data in Figure $1 \mathrm{H}, \zeta_{1}, \zeta_{2}, a, b$ and $m$ values are found to be $-42.3,2.4,11.3,-0.1$ and 0.32 respectively. This expression with high positive constant $a$ (11.3) confirms the role of $\mathrm{Au}^{+}-$thioether interaction in the sharp enhancement of the $\zeta$ potential within $1 \mathrm{mM}$ Met concentration. On the other hand, the negative negligible value of constant $b(-0.1)$ due to $\mathrm{Au}^{0}$-amine interaction ${ }^{40}$ is responsible for slow enhancement significantly after $1 \mathrm{mM}$ Met concentration. The deconvolution spectra of sulfur XPS for $2 \mathrm{p}_{3 / 2}$ and $2 \mathrm{p}_{1 / 2}$ after the growth reaction clearly indicates that $30 \%$ of total sulfur is present for stabilizing $\mathrm{Au}^{+}$ interactions, while the remaining $70 \%$ is similar to the free methionine (Figure S14). Similar to the sulfur XPS, this 0.32 mole fraction (m) of total Met in equation 1 confirms the role of Met for $\mathrm{Au}^{+}$stabilization. The $\zeta$ potential expression, containing the first part of the equation only, results in saturation within $0.5 \mathrm{mM}$ to $15 \mathrm{mM}$ Met concentration range (Figure S15). On the other hand, 
$\zeta$ potential trend with added $\mathrm{Au}^{3+}$ concentration (Figure S16) follows equation (2) in presence of $9 \mathrm{mM}$ Met.

$$
\zeta=\zeta^{\prime}+c\left[\mathrm{Au}^{3+}\right]^{k}
$$

where, $\zeta^{\prime}(-39.5 \mathrm{mV})$ is the $\zeta$ potential before addition of $\mathrm{Au}^{3+}, c(4.5)$ is coefficient and $k(0.40)$ is the Met dependent conversion factor from $\mathrm{Au}^{3+}$ to $\mathrm{Au}^{+}$and $\mathrm{Au}^{0}$.

In addition to the $\mathrm{Au}^{+}-$thioether interaction, absence of the Met carboxylate stretching ${ }^{41}$ frequency at $2116 \mathrm{~cm}^{-1}$ in infrared spectrum confirms the interaction between $\mathrm{Au}^{+}$and carboxylate anion in the self-assembled nucleated particles (Figure S17). The presence of a less intense peak at the same position detected in the infrared spectrum confirms weak interaction prevailing between $\mathrm{Au}^{0}$ and Met carboxylate after the 30 min incubation of Met to the parent AuNP seed. In anticipation of behavior analogous to the Met selective secondary nucleation inhibition process followed by self-assembly, we have investigated a few other sulfur containing molecules and inorganic salts such as 6-mercaptohexanoic acid (1), 3-mercaptopropionic acid (2), ethyl 4-amino2-(methylthio)pyrimidine-5-carboxylate (3), lipoic acid (4), oxidized and reduced glutathione $(5,6)$, sodium sulfate $(7)$ and sodium thiosulfate $(8)$. We have observed the classical growth of the parent AuNP seed producing the spherical gold nanoparticle of 16-18 nm diameter (Figure 2A, S18 and S19) after the growth reactions in presence of 1-8 without any positive $\zeta$ potential data. In the cases of oxidized and reduced glutathione, aggregations of the particles after growth have been observed without any self-assembled geometry. Worth mentioning, the thiol containing amino acid cysteine behaved completely different in the similar growth reaction. ${ }^{35}$

Time dependent nonclassical crystal growth within self-assembled nAuNPs. In order to monitor the effect of the reaction time on the nAuNP formation and their size, incubation time of 
(A)

(1)<smiles>O=C(O)CCS</smiles>

(2)<smiles>CCOC(=O)c1cnc(SC)nc1N</smiles><smiles>O=C(O)CCCCC1CCSS1</smiles><smiles>N[C@@H](CCC(=O)NC(CSSC[C@H](NC(=O)CC[C@H](N)C(=O)O)C(=O)NCC(=O)O)C(=O)NCC(=O)O)C(=O)O</smiles><smiles>N[C@@H](CCC(=O)NC(C[Hg])C(=O)NCC(=O)O)C(=O)O</smiles>

$\mathrm{Na}_{2} \mathrm{SO}_{4} \quad \mathrm{Na}_{2} \mathrm{~S}_{2} \mathrm{O}_{3}$

(7) $\quad$ (8)

(5)

i) $1-8(9 \mathrm{mM})^{*}$
$30 \mathrm{~min}$ incubation ii) $\mathrm{NH}_{2} \mathrm{OH}$
iii) $\mathrm{HAuCl}_{4}$

AuNP Seed

Growth time

"Classical growth"
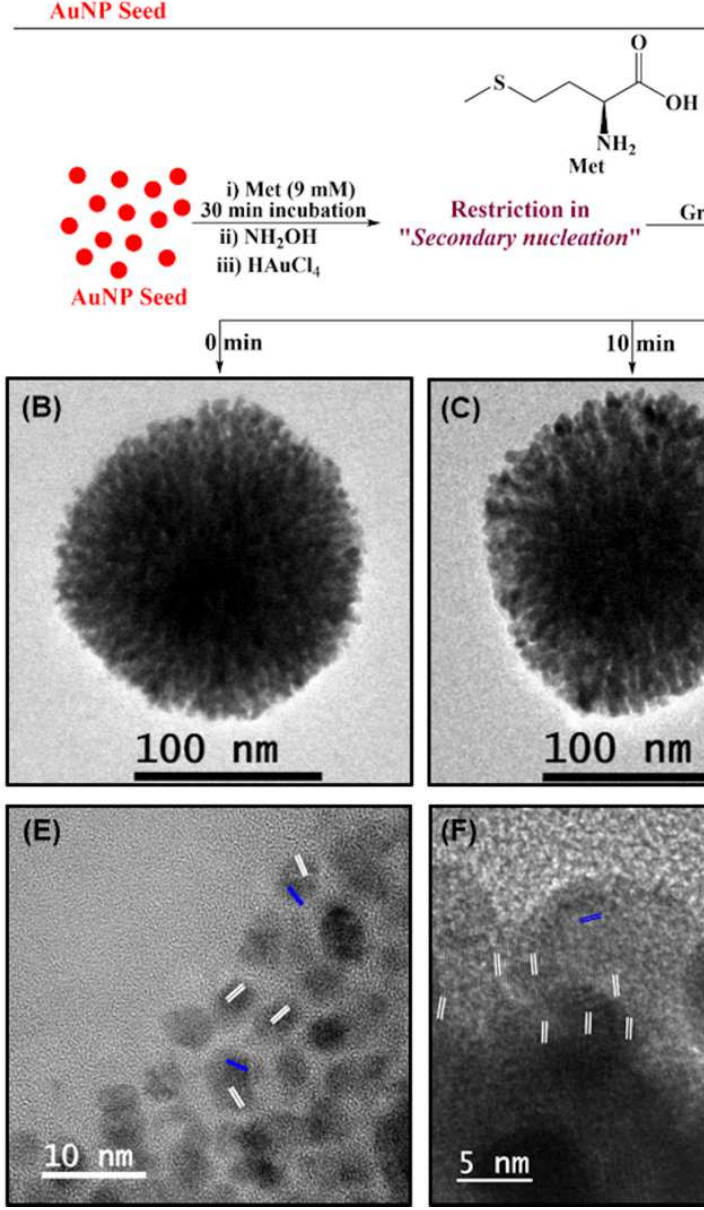

1- 8 have been treated separately
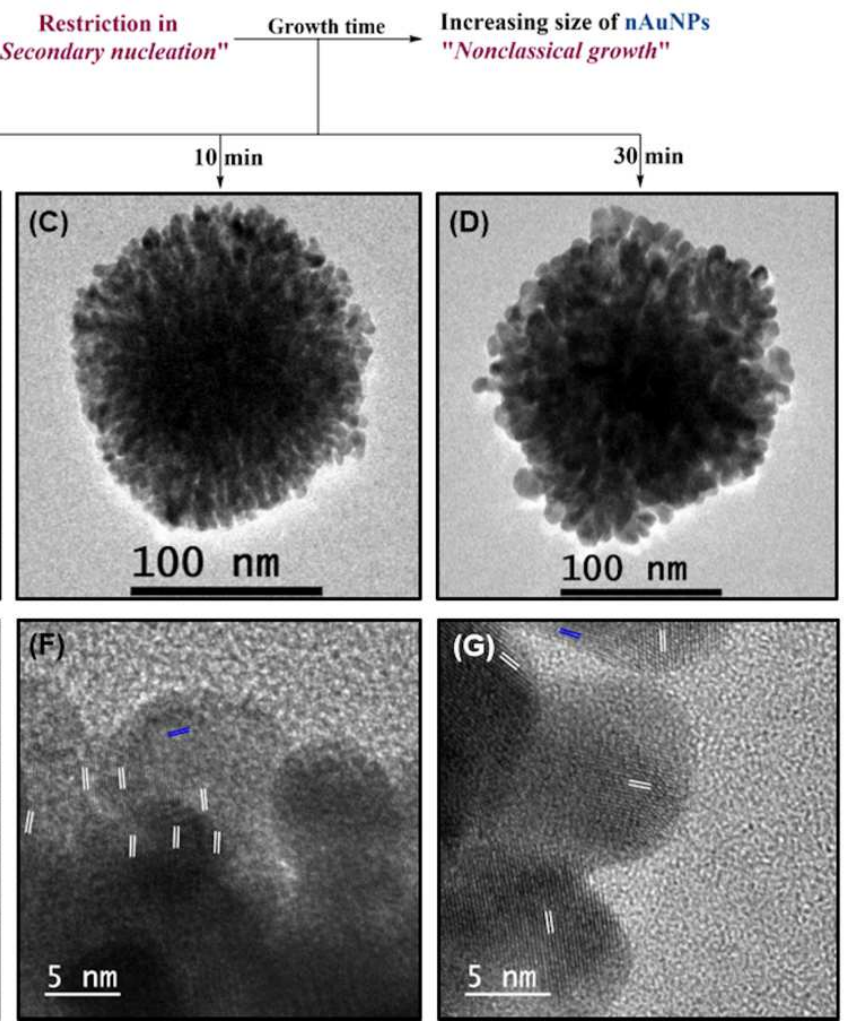

Figure 2: (A) Classical growth of AuNP in presence of 1-8 and Met controlled nonclassical growth, (B-D) TEM and (E-G) HRTEM images of the Met incubated self-assembled nAuNPs at different time interval after the growth reaction for nonclassical growth; the average sizes of each nAuNPs are $(B, E) \sim 3.5 \mathrm{~nm}$ at $0 \mathrm{~min},(\mathrm{C}, \mathrm{F}) \sim 7.0 \mathrm{~nm}$ at $10 \mathrm{~min}$ and $(\mathrm{D}, \mathrm{G}) \sim 11 \mathrm{~nm}$ at $30 \mathrm{~min}$ after the growth reaction of $1.2 \mathrm{nM}$ AuNP in presence of $9 \mathrm{mM}$ Met and $300 \mu \mathrm{M} \mathrm{Au}{ }^{3+}$; $(\mathrm{E}-\mathrm{G})$ displaying (lll 111 ) planes (white lines) in the self-assembled nAuNPs responsible for the nonclassical growth through assembly and merging along with (2 000$)$ planes (blue lines). 
Met with AuNP (Figure S20 and S21) and the growth reaction time after the addition of the $\mathrm{Au}^{3+}$ salt in the solution (Figure 2 and S22) have been varied separately keeping the other time parameter as constant. By performing the growth reaction for $30 \mathrm{~min}$ immediately after addition of Met to AuNP shows aggregation of the seed followed by small-scale formation of nAuNPs. Formation of smaller self-assembled nAuNPs has been observed in the case of 5 min incubation of Met. The maximum size of the self-assembled nAuNPs has been achieved within 10 min incubation of Met with AuNP. Keeping the incubation time of Met with AuNP as 30 min, immediately after the addition of $\mathrm{Au}^{3+}$ salt, shows the formation of spherical self-assembly in TEM (Figure 2B). Size and $\zeta$ potential of the self-assembled nAuNPs remains unchanged even after 30 min of the growth reaction (Scheme 1, condition 5-7). However, the average size for each nAuNP increases from $\sim 3.5 \mathrm{~nm}$ to $\sim 11 \mathrm{~nm}$ during 30 min growth reaction (Figure 2B-D). HRTEM imaging captured at different time frames suggests the growth of nAuNPs through ( $\left(\begin{array}{lll}1 & 1 & 1\end{array}\right)$ crystal planes via oriented attachment leading to the nonclassical crystal growth (Figure 2E-G). This change in each nucleated particle size is nonclassical ${ }^{6}$ in nature, where kinetically controlled growth by assembly and merging is responsible for the formation of larger nAuNPs.

Methionine containing peptides in secondary nucleation inhibition. Finally, Met containing peptides have been investigated for a comprehensive understanding of the development of nAuNPs in presence of peptide amide bonds with other amino acid. Poor water solubility of hydrophobic Met unit within a peptide restricts the choice of targeted peptide sequences with decameric amino acids. Three peptide sequences $\mathrm{M}_{1}, \mathrm{M}_{3}$ and $\mathrm{M}_{5}$ [Ac-MAAAAAAAAA- $\mathrm{NH}_{2}\left(\mathrm{M}_{1}\right)$, AcMAAAMAAAAM-NH${ }_{2}\left(\mathrm{M}_{3}\right)$ and Ac-MAMAMAMAMA- $\left.\mathrm{NH}_{2}\left(\mathrm{M}_{5}\right)\right]$ have been chosen with one, three and five Met units respectively on the basis of the availability of these sequences in 
proteins. ${ }^{42-44}$ Growth reaction in presence of $300 \mu \mathrm{M} \mathrm{M}_{1}$ peptide shows broad absorbance spectrum (Figure 3A and S23), whereas the growth reactions after the treatment with the same concentration of $\mathrm{M}_{3}$ and $\mathrm{M}_{5}$ results in the development of additional peak around $680 \mathrm{~nm}$ and $710 \mathrm{~nm}$ respectively. The luminescence measurements at $430 \mathrm{~nm}$ after the growth reaction with these

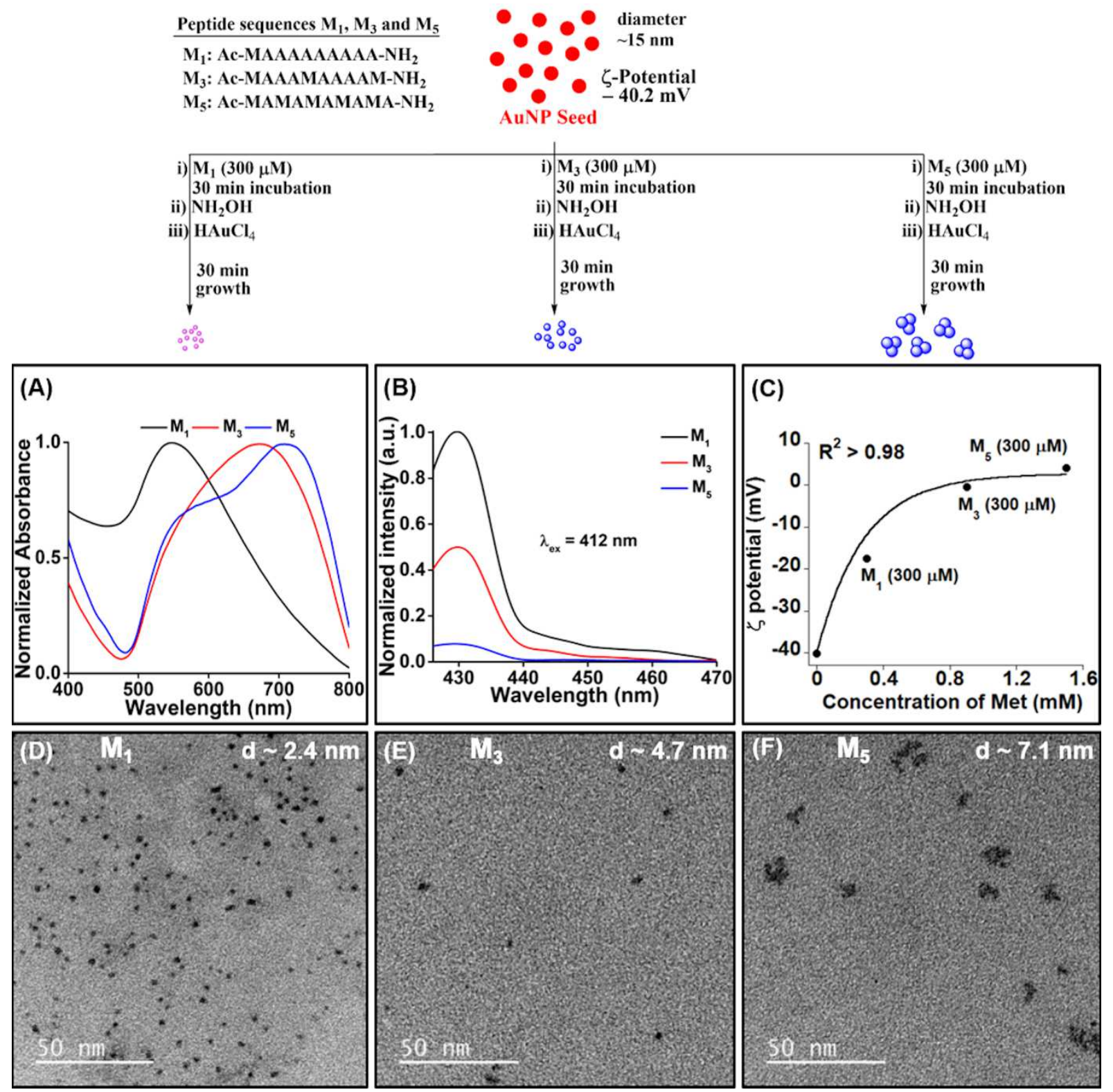

Figure 3: Formation of nAuNPs after the growth reactions of AuNPs in presence Met containing peptides $\mathrm{M}_{1}, \mathrm{M}_{3}, \mathrm{M}_{5}$; (A) absorbance spectra, (B) emission spectra, (C) fitting of $\zeta$ potential values with the proposed equation (1) and (D-F) TEM images (scale bar $50 \mathrm{~nm}$ ) of nAuNPs after 30 min growth reaction of $1.2 \mathrm{nM}$ AuNP in presence of $300 \mu \mathrm{M} \mathrm{M}_{1}, \mathrm{M}_{3}, \mathrm{M}_{5}$ and $300 \mu \mathrm{M} \mathrm{Au}^{3+}$. 
peptides confirm the decreasing trend of emission intensities from $M_{1}$ to $M_{5}$ peptides (Figure 3B). The increasing trend of $\zeta$ potential $\left(\mathrm{M}_{1}:-17.6 \mathrm{mV}, \mathrm{M}_{3}:-0.5 \mathrm{mV}\right.$ and $\left.\mathrm{M}_{5}:+4.1 \mathrm{mV}\right)$ after the growth reactions in presence of these three peptides also follows the equation 1 (Figure 3C) depending upon the total Met residues in the solutions.

TEM images after the growth reactions with $\mathrm{M}_{1}$ peptide shows the formation of nAuNPs of average size $2.4 \mathrm{~nm}$ (Figure 3D). Similar studies with $\mathrm{M}_{3}$ and $\mathrm{M}_{5}$ peptides display the $\mathrm{nAuNPs}$ of $4.7 \mathrm{~nm}$ and $7.1 \mathrm{~nm}$ respectively (Figure 3E-F). In addition, small self-assembly of nAuNPs has been observed only after the growth in presence of $\mathrm{M}_{5}$ peptide. Formation of self-assemblies through nAuNPs are restricted in $\mathrm{M}_{1}$ and $\mathrm{M}_{3}$ peptides due to additional Ala residues in these peptides. Alanine in these peptide sequences show non-invasive behavior during the growth reaction of AuNPs. The enhanced size of nAuNPs is responsible for poor emission in the case of $\mathrm{M}_{3}$. In addition to the enhanced size of nAuNPs, formation of self-assembly is also responsible for very weak emission after the growth reaction in presence of $\mathrm{M}_{5}$.

Conclusions. In this work, the selective formation of self-assembled nAuNPs has been demonstrated by restricting the secondary nucleation through Met stabilized $\mathrm{Au}^{+}$, on contrary to the conventional growth reaction of AuNP seed. The restriction in the self-assembly of nAuNPs has been achieved either by introducing less amount of $\mathrm{Met}$ or $\mathrm{Au}^{3+}$ salt in the growth reaction and reducing the reaction time. The segregated nAuNPs are emissive in nature, which has quenched with time due to nonclassical growth and self-assembly. In presence of neutral Met, this weakly emissive self-assembled nanoarchitecture shows positive $\zeta$ potential after the growth reaction, whereas the parent AuNP seed has negative $\zeta$ potential. Dramatic change in $\zeta$ potential has been correlated with Met concentration, where a certain fraction of Met participates in $\mathrm{Au}^{+}$stabilization 
through its thioether functional group. The time dependent nonclassical growth through aggregation and merging of nAuNPs within the self-assembly has been clearly observed through TEM imaging. This inhibition of secondary nucleation process and nonclassical growth have been successfully explored with bio-inspired decameric peptides having Met and Ala sequences. These findings open the possibility of exploring thioether functional group in the growth reaction of gold nanoparticle, for example in developing anisotropic shape within nucleated particles of smaller dimension compared to the parent seed.

\section{Supporting Information}

The supporting information contains instrumental information and Figures S1-S23.

\section{References:}

1. Scarabelli, L., Sánchez-Iglesias, A., Pérez-Juste, J. \& Liz-Marzán, L. M. A “Tips and Tricks" practical guide to the synthesis of gold nanorods. J. Phys. Chem. Lett. 6, 42704279 (2015).

2. Thacker, D. et al. The role of fibril structure and surface hydrophobicity in secondary nucleation of amyloid fibrils. Proc. Natl. Acad. Sci. U.S.A. 117, 25272-25283 (2020).

3. Habchi, J. et al. Systematic development of small molecules to inhibit specific microscopic steps of A $\beta 42$ aggregation in Alzheimer's disease. Proc. Natl.Acad.Sci.U.S.A. 114, E200E208 (2017).

4. Li, Y. et al. Corner-, edge-, and facet-controlled growth of nanocrystals. Sci. Adv. 7, eabf1410 (2021).

5. Janicek, B. E. et al. Quantitative imaging of organic ligand density on anisotropic inorganic nanocrystals. Nano Lett. 19, 6308-6314 (2019).

6. Lee, J., Yang, J., Kwon, S. G. \& Hyeon, T. Nonclassical nucleation and growth of inorganic nanoparticles. Nat. Rev. Mater. 1, 16034 (2016).

7. Yao, Q. et al. Understanding seed-mediated growth of gold nanoclusters at molecular level. Nat. Commun. 8, 927 (2017).

8. Wang, J., Chen, S., Cui, K., Li, D. \& Chen, D. Approach and coalescence of gold nanoparticles driven by surface thermodynamic fluctuations and atomic interaction forces. ACS Nano 10, 2893-2902 (2016). 
9. Dachraoui, W., Keller, D., Henninen, T. R., Ashton, O. J. \& Erni, R. Atomic mechanisms of nanocrystallization via cluster-clouds in solution studied by liquid-phase scanning transmission electron microscopy. Nano Lett. 21, 2861-2869 (2021).

10. Ramamoorthy, R. K. et al. The role of pre-nucleation in the crystallization of gold nanoparticles. Nanoscale 12, 16173-16188 (2020).

11. Langille, M. R., Personick, M. L., Zhang, J. \& Mirkin, C. A. Defining rules for the shape evolution of gold nanoparticles. J. Am. Chem. Soc. 134, 14542-14554 (2012).

12. Lohse, S. E., Burrows, N. D., Scarabelli, L., Liz-Marzán, L. M. \& Murphy, C. J. Anisotropic noble metal nanocrystal growth: The role of halides. Chem. Mater. 26, 34-43 (2014).

13. Niu, W., Chua, Y. A. A., Zhang, W., Huang, H. \& Lu, X. Highly symmetric gold nanostars: Crystallographic control and surface-enhanced raman scattering property. J. Am. Chem. Soc. 137, 10460-10463 (2015).

14. Chiu, C.-Y., Ruana, L. \& Huang, Y. Biomolecular specificity-controlled nanomaterial synthesis. Chem. Soc. Rev. 42, 2512-2527 (2013).

15. Mokashi-Punekar, S., Walsh, T. R. \& Rosi, N. L. Tuning the structure and chiroptical properties of gold nanoparticle single helices via peptide sequence variation. J. Am. Chem. Soc. 141, 15710-15716 (2019).

16. Tanwar, S., Haldar, K. K. \& Sen, T. DNA origami directed Au nanostar dimers for singlemolecule surface-enhanced raman scattering. J. Am. Chem. Soc. 139, 17639-17648 (2017).

17. Bousmail, D., Chidchob, P. \& Sleiman, H. F. Cyanine-mediated DNA nanofiber growth with controlled dimensionality. J. Am. Chem. Soc. 140, 9518-9530 (2018).

18. Shen, B. et al. Plasmonic nanostructures through DNA-assisted lithography Sci. Adv. 4, eaap8978 (2018).

19. Yan, F. et al. Controlled synthesis of highly-branched plasmonic gold nanoparticles through peptoid engineering. Nat. Commun. 9, 2327 (2018).

20. Laramy, C. R. et al. Controlled symmetry breaking in colloidal crystal engineering with DNA. ACS Nano 13, 1412-1420 (2019).

21. Ma, X. et al. Gold nanocrystals with DNA-directed morphologies. Nat. Commun. 7, 12873 (2016).

22. Satyavolu, N. S. R., Tan, L. H. \& Lu, Y. DNA-mediated morphological control of Pd-Au bimetallic nanoparticles. J. Am. Chem. Soc. 138, 16542-16548 (2016). 
23. Lee, H.-E. et al. Amino-acid- and peptide-directed synthesis of chiral plasmonic gold nanoparticles. Nature 556, 360-365 (2018).

24. Cho, N. H. et al. Uniform chiral gap synthesis for high dissymmetry factor in single plasmonic gold nanoparticle. ACS Nano 14, 3595-3602 (2020).

25. Zeng, C., Zhou, M., Chen, Y.\& Jin, R. Atomically precise colloidal metal nanoclusters and nanoparticles: Fundamentals and opportunities. Chem. Rev. 116, 10346-10413 (2016).

26. Kang, H. et al. Stabilization of silver and gold nanoparticles: Preservation and improvement of plasmonic functionalities. Chem. Rev. 119, 664-699 (2019).

27. Pearce, A. K., Wilks, T. R., Arno, M. C. \& O’Reilly, R. K. Synthesis and applications of anisotropic nanoparticles with precisely defined dimensions. Nat. Rev. Chem. 5, 21-45 (2021).

28. González-Rubio, G. et al. Micelle-directed chiral seeded growth on anisotropic gold nanocrystals. Science 368, 1472-1477 (2020).

29. Wang, Y. et. Al. Quantitative analysis of DNA-mediated formation of metal nanocrystals. J. Am. Chem. Soc. 142, 20368-20379 (2020).

30. Walsh, M. J. et al. A mechanism for symmetry breaking and shape control in single-crystal gold nanorods. Acc. Chem. Res. 50, 2925-2935 (2017).

31. Wang, Q. et al. Controlled growth and shape-directed self-assembly of gold nanoarrows. Sci. Adv. 3, e1701183 (2017).

32. Zhai, Y. et al. Polyvinylpyrrolidone-induced anisotropic growth of gold nanoprisms in plasmon-driven synthesis. Nat. Mater. 15, 889-895 (2016).

33. Lee, J.-H., Gibson, K. J., Chen, G. \& Weizmann, Y. Bipyramid-templated synthesis of monodisperse anisotropic gold nanocrystals. Nat. Commun. 6, 7571 (2015).

34. Lee, H.-E. et al. Concave rhombic dodecahedral Au nanocatalyst with multiple high-index facets for $\mathrm{CO}_{2}$ reduction. ACS Nano 9, 8384-8393 (2015).

35. Lone, S. A. \& Sadhu, K. K. Gold nanoflower for selective detection of single arginine effect in $\alpha$-helix conformational change over lysine in $3_{10}$-helix peptide. Bioconjugate Chem. 30, 1781-1787 (2019).

36. Isab, A. A. \& Sadler, P. J. Reactions of gold(III) ions with ribonuclease A and methionine derivatives in aqueous solution. Biochim. Biophys. Acta 492, 322-330 (1977). 
37. Wang, W. et al. Engineering the protein corona structure on gold nanoclusters enables redshifted emissions in the second near-infrared window for gastrointestinal imaging. Angew . Chem. Int. Ed. 59, 22431-22435 (2020).

38. Luo, Z. et al. From aggregation-induced emission of $\mathrm{Au}(\mathrm{I})$-thiolate complexes to ultrabright $\mathrm{Au}(0) @ \mathrm{Au}(\mathrm{I})$-thiolate core-shell nanoclusters. J. Am. Chem. Soc. 134, 16662-16670 (2012).

39. $\mathrm{Wu}, \mathrm{Z}$. et al. Aurophilic interactions in the self-assembly of gold nanoclusters into nanoribbons with enhanced luminescence. Angew. Chem. Int. Ed. 58, 8139-8144 (2019).

40. Laban, B. et al. Green synthesis and characterization of nontoxic L-methionine capped silver and gold nanoparticles. J. Inorg. Biochem. 204, 110958 (2020).

41. Cao, X. \& Fischer, G. Conformational and infrared spectral studies of L-methionine and its N-deuterated isotopomer as isolated zwitterions. J. Phys. Chem. A 106, 41-50 (2002).

42. Lingaraju, G. M. et al. Crystal structure of the human COP9 signalosome. Nature 512, 161165 (2014).

43. Lavrinienko, A. et al. Two hundred and fifty-four metagenome-assembled bacterial genomes from the bank vole gut microbiota. Sci.Data 7, 312 (2020).

44. Bi, X. et al. Tracing the genetic footprints of vertebrate landing in non-teleost ray-finned fishes. Cell 184, 1377-1391 (2021).

\section{Methods}

Synthesis of AuNP seed stock solution

$20 \mathrm{mg}(0.05 \mathrm{mmol})$ of $\mathrm{HAuCl}_{4}$ was dissolved in $90 \mathrm{~mL}$ of deionized water and refluxed at $90^{\circ} \mathrm{C}$. $10 \mathrm{~mL}$ of $1 \%(\mathrm{w} / \mathrm{v})$ trisodium citrate dihydrate $(88 \mathrm{mg}, 0.3 \mathrm{mmol})$ was added to the above solution. After few minutes the color of the solution was changed to dark violet and then immediately changed to wine red. The reaction was continued for another 30 minutes in the refluxing condition and finally stopped. The AuNP solution was cooled to room temperature and the solution was characterized with the help of absorption spectroscopy and TEM image. The stock solution was stored at $4{ }^{\circ} \mathrm{C}$ till further use. For further experiments the seed solution was diluted and the final concentration of the solution was measured as per our previous report. ${ }^{35}$

\section{Growth reaction of AuNP with Met and high concentration of gold salt}

$300 \mu \mathrm{L}$ gold nanoparticles seed stock solution was incubated for 30 min with $30 \mu \mathrm{L}$ of $100 \mathrm{mM}$ Met. During the incubation period the color of the solution gradually changed towards reddish violet. Thereafter, $3 \mu \mathrm{L}$ of $200 \mathrm{mM} \mathrm{NH}_{2} \mathrm{OH}$ (pH 5 maintained with addition of $\mathrm{NaOH}$ ) was added to the above solutions and stirred vigorously for $10 \mathrm{~min}$ followed by the addition of $5 \mu \mathrm{L}$ of $0.8 \%$ $(\mathrm{w} / \mathrm{v}) \mathrm{HAuCl}_{4}$ to induce the reduction reaction. In each case, the final volume of the reaction was adjusted to $340 \mu \mathrm{L}$. After addition of gold salt, the reddish violet color immediately changed to blue. The solution was analyzed up to $30 \mathrm{~min}$ by different characterization techniques. 


\section{Growth reaction of AuNP with Met with variable concentration of gold salt}

Different sets of $900 \mu \mathrm{L}$ gold nanoparticles seed solution were incubated separately for $30 \mathrm{~min}$ with $90 \mu \mathrm{L}$ of $100 \mathrm{mM}$ Met. During the incubation period the color of the solutions gradually changed towards reddish violet. Thereafter, $9 \mu \mathrm{L}$ of $200 \mathrm{mM} \mathrm{NH}_{2} \mathrm{OH}$ (pH 5 maintained with addition of $\mathrm{NaOH}$ ) was added to the above solutions and stirred vigorously for 10 min followed by the addition of variable amount $(0.5-50 \mu \mathrm{L})$ of $0.8 \%(\mathrm{w} / \mathrm{v}) \mathrm{HAuCl}_{4}$ to induce the reduction reaction. In these cases, the final volume of the reactions was adjusted to $1020 \mu \mathrm{L}$ by addition of deionized water. After addition of gold salt, the reddish violet color immediately changed to blue. The solution was analyzed up to $30 \mathrm{~min}$ by different characterization techniques.

\section{Growth reactions of AuNP with variable concentration of Met}

Different sets of $900 \mu \mathrm{L}$ gold nanoparticles seed solution were incubated separately for $30 \mathrm{~min}$ with $1 \mu \mathrm{L}, 3 \mu \mathrm{L}, 5 \mu \mathrm{L}, 10 \mu \mathrm{L}, 30 \mu \mathrm{L}, 60 \mu \mathrm{L}$ and $90 \mu \mathrm{L}$ of $100 \mathrm{mM}$ Met and $60 \mu \mathrm{L}$ and $75 \mu \mathrm{L}$ of $200 \mathrm{mM}$ Met, where the final Met concentration were maintained to $0.1 \mathrm{mM}, 0.3 \mathrm{mM}, 0.5 \mathrm{mM}, 1$ $\mathrm{mM}, 3 \mathrm{mM}, 6 \mathrm{mM}, 9 \mathrm{mM}, 12 \mathrm{mM}$ and $15 \mathrm{mM}$ respectively. During the incubation period the color of the solution gradually changed towards reddish violet at high concentration ( $3 \mathrm{mM}$ to $15 \mathrm{mM}$ ), whereas the at low concentration $(0.1 \mathrm{mM}$ to $1 \mathrm{mM})$ there was no change in color. Thereafter, 9 $\mu \mathrm{L}$ of $200 \mathrm{mM} \mathrm{NH}_{2} \mathrm{OH}$ ( $\mathrm{pH} 5$ maintained with addition of $\mathrm{NaOH}$ ) was added to the above solutions and stirred vigorously for 10 min followed by the addition of $15 \mu \mathrm{L}$ of $0.8 \%(\mathrm{w} / \mathrm{v}) \mathrm{HAuCl}_{4}$ to induce the reduction reaction. In these cases, the final volume of each reaction was adjusted to $1020 \mu \mathrm{L}$ by addition of deionized water. After addition of gold salt, the reddish violet or red color immediately changes to blue. The solutions were analyzed up to $30 \mathrm{~min}$ by different characterization techniques.

\section{Growth reactions of AuNP with variable incubation time of Met}

Different sets of $300 \mu \mathrm{L}$ gold nanoparticles seed solution were incubated for $0 \mathrm{~min}, 5 \mathrm{~min}$ and 10 min separately with $30 \mu \mathrm{L}$ of $100 \mathrm{mM}$ Met. During the incubation period the color of the solution remained unchanged up to $10 \mathrm{~min}$. There was gradually change in color towards reddish violet after $10 \mathrm{~min}$. Thereafter, $3 \mu \mathrm{L}$ of $200 \mathrm{mM} \mathrm{NH}_{2} \mathrm{OH}(\mathrm{pH} 5$ maintained with addition of $\mathrm{NaOH}$ ) was added to the above solutions and stirred vigorously for $10 \mathrm{~min}$ followed by the addition of $5 \mu \mathrm{L}$ of $0.8 \%(\mathrm{w} / \mathrm{v}) \mathrm{HAuCl}_{4}$ to induce the reduction reaction. In each case, the final volume of the reaction was adjusted to $340 \mu \mathrm{L}$. After addition of gold salt, the red color immediately changed to blue. The solutions were analyzed up to $30 \mathrm{~min}$ by different characterization techniques.

\section{Growth reactions of AuNP with Met containing peptides ( $M_{1}, M_{3}$ and $\left.M_{5}\right)$}

$5 \mathrm{mM}$ stock solutions of $\mathrm{M}_{1}, \mathrm{M}_{3}$ and $\mathrm{M}_{5}$ were prepared separately in DMSO due to hydrophobic nature of Met. Three sets of $300 \mu \mathrm{L}$ gold nanoparticles seed solution were incubated for $30 \mathrm{~min}$ with $20 \mu \mathrm{L}$ of $5 \mathrm{mM} \mathrm{M}, \mathrm{M}_{3}$ and $\mathrm{M}_{5}$ peptides. During the incubation period the color of the solutions gradually changed towards reddish violet for $\mathrm{M}_{3}$ and $\mathrm{M}_{5}$ peptides with high Met content. Thereafter, $3 \mu \mathrm{L}$ of $200 \mathrm{mM} \mathrm{NH}_{2} \mathrm{OH}$ (pH 5 maintained with addition of $\mathrm{NaOH}$ ) was added to the above solutions and stirred vigorously for 10 min followed by the addition of $5 \mu \mathrm{L}$ of $0.8 \%(\mathrm{w} / \mathrm{v}$ ) $\mathrm{HAuCl}_{4}$ to induce the reduction reaction. In each case, the final volume of the reaction was adjusted to $340 \mu \mathrm{L}$. After addition of gold salt, the reddish violet color immediately changes to blue. The solutions were analyzed up to $30 \mathrm{~min}$ by different characterization techniques. 
Growth reactions of AuNP with sulfur containing small molecules and salts (1-8)

Stock solutions of $100 \mathrm{mM}$ 6-mercaptohexanoic acid (1), 3-mercaptopropionic acid (2), ethyl 4amino-2-(methylthio)pyrimidine-5-carboxylate (3, thioether nucleic base), lipoic acid (4), oxidized and reduced glutathione $(5,6)$, sodium sulfate (7) and sodium thiosulfate (8) were prepared either in deionized water or $50 \%$ ethanol in deionized water. Different sets of $300 \mu \mathrm{L}$ gold nanoparticles seed solution were incubated separately for 30 min with $30 \mu \mathrm{L} 100 \mathrm{mM}$ of 18 , where the final concentration was maintained to $9 \mathrm{mM}$. Thereafter, $3 \mu \mathrm{L}$ of $200 \mathrm{mM} \mathrm{NH}_{2} \mathrm{OH}$ ( $\mathrm{pH} 5$ maintained with addition of $\mathrm{NaOH}$ ) was added to the above solutions and stirred vigorously for $10 \mathrm{~min}$ followed by the addition of $5 \mu \mathrm{L}$ of $0.8 \%(\mathrm{w} / \mathrm{v}) \mathrm{HAuCl}_{4}$ to induce the reduction reaction. In each case, the final volume of the reaction was adjusted to $340 \mu \mathrm{L}$. After addition of gold salt, the color of all of each solution immediately changed to blue except the solution containing 4,7 and 8 . The solutions were analyzed up to $30 \mathrm{~min}$ by different characterization techniques. In case of 4 , the SPR peak intensity was enhanced significantly with broadening. In case of 7, the SPR peak intensity was enhanced slightly. However, in case of 8 , there was no color change.

\section{Author Contributions}

K.K.S. conceived the idea. S.A.L. performed the experiments with self-assembled nAuNPs having positive $\zeta$ potential. J.K.S. performed all the detail mechanistic studies. J.K.S and K.K.S. carried out the data analysis and wrote the manuscript. All authors discussed the results and commented on the manuscript.

\section{Notes}

The authors declare no competing financial interest.

\section{ACKNOWLEDGEMENTS}

K.K.S. acknowledges the DST Nanomission (DST/NM/NB/2018/237) and SERB-DST Grant (CRG/2018/000269) for funding. 


\section{Supplementary Files}

This is a list of supplementary files associated with this preprint. Click to download.

- SI.pdf 